\title{
THE INFLUENCE OF DESIGN BRIEF INFORMATION ON CREATIVE OUTCOMES BY NOVICE AND ADVANCED STUDENTS
}

\author{
Koronis, Georgios (1); \\ Casakin, Hernan (2); \\ Silva, Arlindo (1); \\ Kang, Jacob Kai Siang (1) \\ 1: Singapore University of Technology and Design; \\ 2: Ariel University
}

\begin{abstract}
This study centers on using different types of brief information to support creative outcomes in architectural and engineering design and its relation to design expertise. We explore the influence of design briefs characterized by abstract representations and/or instructions to frame design problems on the creativity of concept sketches produced by novice and advanced students. Abstract representations of problem requirements served as stimuli to encourage associative thinking and knowledge transfer. The Ishikawa/Fishbone Diagram was used to foster design restructuring and to modify viewpoints about the main design drives and goals. The design outcomes generated by novice and advanced engineering/architecture students were assessed for their creativity using a pairwise experimental design. Results indicated that advanced students generated more novel design solutions while also contributing the most useful solutions overall. Implications for creativity in design education and professional practice are presented. Educational programs aimed at promoting creativity in the design studio may find it helpful to consider that the way design briefs are constructed can either promote or inhibit different aspects of design creativity.
\end{abstract}

Keywords: Creativity, Education, Conceptual design, Abstract representation, Reframing

\section{Contact:}

Koronis, Georgios

Singapore University of Technology and Design

Singapore

georgios_koronis@sutd.edu.sg 


\section{INTRODUCTION}

Creativity is concerned with the generation of novel and useful ideas that are related to specific products, processes, and procedures (Amabile, 1982). Creativity research is vast and includes many different disciplines that span from social and behavioral sciences to engineering, architecture, and design. One of the reasons measuring creativity is challenging is because design problems are illstructured, ambiguous, and unique; hence many solutions are possible (Rittel \& Melving, 1984). It is in the design studio where students acquire theoretical and practical knowledge and forge their skills and abilities while developing the expertise to cope with increasingly complex tasks demanding creativity (Casakin \& Kreitler, 2008). Indeed, the way students approach design problems largely depends on how tasks are initially represented, what information is provided, and how design briefs are framed. However, scarce literature exists about what constitutes an efficient design brief and how its structuring could affect the creativity of the produced outcomes (Meurzec et al., 2019). To address this gap, we empirically manipulated the structure of design briefs to provide information based on abstract representations and provide instructions to frame and reframe the design task using the Ishikawa/Fishbone Diagram method (Ishikawa, 1982). Abstract representations (Linsey et al., 2010) and restructuring (Moreno et al., 2016) tools were found to improve design ideation potentials. The importance of this research resides in understanding how briefs can aid in enhancing the creativity of design outcomes and how this relates to the level of expertise of design students. Understanding participants' baseline skills, expertise, and motivation is an essential step in designing interventions aimed at increasing creativity (Ree et al., 1995).

\section{BACKGROUND}

\subsection{Design ideas and creativity - Novelty and Usefulness}

Creative thinking is essential to improve the skills required to deal with non-routine design problems (Coyne, 1997). It is also the cognitive ability required to generate frequent and high-quality ideas (Hong \& Milgram, 2008). At the outset of the design activity, creative thinking can be considered the most inventive and exploratory phase, which can be enhanced as designers develop their abilities to generate alternative idea solutions. In design literature, creativity can be operationalized and evaluated by employing Novelty and Usefulness metrics (Madni, 2012). Novelty is defined as the extent to which a product or outcome is new and different in an interesting way from known and familiar designs. A novel product is also expected to be surprising and appealing (Derbaix \& Vanhamme, 2003). Besides being novel and be recognized as valuable, creative designs must also be useful (Sarkar \& Chakrabarti, 2011). Therefore, Usefulness can be defined as the efficiency and performance of a product. Hence, useful design outcomes must be aligned with the needs and requirements as specified by the design brief (Siang et al., 2018).

\subsection{Design expertise and creativity: novices and advanced students}

The most important aim of design education is to stimulate and help develop creativity. Nurturing creativity is an implicit goal in the design studio, which is by far the place where the central experience of architectural and engineering design students takes place (Boucharenc, 2006). However, a continuing challenge in the design studio environments is promoting creativity and establishing the learning conditions necessary for attaining this aim (Budge et al., 2013). Such conditions may vary depending on the students' experience, skills, and knowledge, which are pre-conditions for acquiring expertise (Dominowski, 1995). Hence, a further concern in design education is how to support the development of design problem-solving expertise. Goncalves et al. (2014) explored what kind of stimuli designers with different levels of expertise use as inspirational sources during the idea generation process. They found that novices tend to rely on textual stimuli for idea generation tasks more than design experts. Casakin (2010) found that irrespectively of whether guidance to use analogy and visual displays was available, advanced students performed more creatively in the generation of design ideas than novices.

Since advanced students have more developed and integrated knowledge structures than novices, they were able to apply abstraction and establish structural mappings between the available stimuli and the design problem. While previous works centered on how creativity in learning environments can be 
stimulated and developed (Craft, 2006), the present study explores how students with different levels of expertise can be supported by crafting design briefs to enhance their design creativity outcomes.

\subsection{The design brief and types of information}

A creative process is often initiated with a stimulating design brief, which is generally available to the designers. It consists of a document outlining the requirements and expectations that should be considered while dealing with the assigned project (Camburn et al., 2017). A project manager often develops briefs in consultation with the client to amalgamate targeted group needs and desired results (Koronis et al., 2020).

In the design studio, the brief describes and communicates in a succinct format what aspects should be achieved for a potential client. To successfully tackle a design problem, students need to be conscious of the task's main goals and priorities. To this aim, a design brief must provide them with guidance and direction through the design process (Chen, 2016; Koronis et al., 2019a). However, teachers may be generally unaware of what resources could help students gain insight into a design assignment. Unsupportive briefs may cause communication and understanding problems and induce a negative motivation for creativity (Casakin and Kreitler, 2010). Hence, what type of information design briefs should contain to enhance students' creativity in design problem-solving should be further investigated. Addressing this gap is critical since the way the content of a brief is represented has a significant impact on the creativity of the solutions generated in the design studio environment (Carlgren et al., 2016; Casakin et al., 2019).

\subsection{External stimuli - abstract representations}

The impact of abstract representations on creativity is a topic of interest across disciplines. In engineering design literature, findings suggest that abstract brief requirements improve idea associations between domains (Linsey et al., 2012). In pedagogy, transferring ideas between domains using visual stimuli can be improved by presenting problems in an abstract, idealized form (Goldstone and Sakamoto 2003). In the design of information systems, abstraction and re-representation have been reported to enhance Novelty while reducing the Usefulness of the ideas (Zahner et al., 2010). A good abstract representation, according to Zahner, "will conform to problem constraints while increasing the range of associations and domains". Among most studies reviewed, abstract stimuli improved Novelty by reducing detailed specifications and replacing them with more general functionbased terminologies in the domain.

\subsection{Framing and reframing and impact on ideation}

Over the past years, the notion of framing and reframing has gained relevance in the design community (Dorst, 2015). In his book "Frame Innovation" Dorst says: "Frame creation is more focused on creating new approaches to the problem situation instead of solution finding," citing as an example reframing an initiative to "reduce criminal activities at night" as a "night festival" that gives local youths the opportunity to engage in a positive way. Framing/Reframing (F/R) problem opportunities in design projects involves sensemaking from other contexts (Valkenburg 2000), formulating new opportunities from surprising observations or interactions, shifting perspectives, challenging assumptions, and active reflection (Schön 1983). As Seelig argues, "All questions are the frame into which the answers fall. By changing the frame, you dramatically change the range of possible solutions."

In protocol studies, shifting frames was found to help develop designs (Schön, 1984) and increase the amount of time spent on problem definition, which was "observed to produce better creative results" (Christiaans \& Venselaar, 2005). Studies of novice and advanced designers show that the latter tend to question assumptions and be more problem-oriented, resulting in higher creative outcomes than in novices, who were more "solution-oriented" (Christiaans \& Dorst, 1992). In design and engineering education literature, framing and reframing have been shown to boost creativity and design cognition (Moreno et al., 2016; Linsey et al., 2008). While the abstract brief shapes the perception of a problem situation using abstract terms, the fishbone method promotes a guided response to reframe the problem and shifts perspectives in the problem space (Ishikawa, 1982). Having a clear framework to guide the formulation of a frame has proven helpful in several of our creativity workshops and courses. The use 
of how-why laddering, Fishbone, and "How-might-we's" (Parnes,1967) have shown to be effective to this aim. We chose Fishbone as a well-established method developed for quality control to identify the underlying root causes of problems.

\section{RESEARCH QUESTIONS}

Besides the studies discussed above, reframing and abstract representations in relation to students' design expertise should be further explored. To this end, a primary aim was to compare novices with advanced students and explore whether potential differences may occur in the learning experience, as reflected in their design outcomes. We will attempt to explain these differences and to address how they can impact the students' development through the curriculum. As such, we wanted to assess whether exposure to reframing and abstract briefs may enhance their creative performance measured by the generation of novel and useful solutions. With this aim in mind, we devised the following research questions:

RQ1. Are there statistical differences between the creative outcomes in the groups of novices and advanced students for each design condition?

RQ2. Are there statistical differences among the design conditions regarding the creative outcomes produced by each group of novice and advanced students?

RQ3. Irrespective of the level of expertise, what are the differences among the design conditions regarding students' creative outcomes as a whole group?

\section{METHODOLOGY}

\subsection{Participants}

The experiment was conducted with novices and advanced students in a university, with a total of 109 first-year undergraduate and final students actively involved. The age of novices ranged between 19 and 21, and that of advanced students was between 22 and 24. Each class of students was randomly assigned to one of the experimental conditions of the Abstract, Fishbone, or Abstract + Fishbone. At the time of the study, the novice students had not yet specified their major or track. In the following year of their studies, they opt for either Architecture and Sustainable Design, Engineering Product Development, Engineering Systems and Design, Information Systems Technology and Design tracks and subsequently for their major within the track. Advanced students were on either of the track's specializations.

\subsection{Conditions and normality tests}

To investigate the influence of briefs on the design outcomes, three varying design briefs (listed in Table 1) of various abstraction and problem restructuring levels are provided to respective groups.

Table 1. Categorization of variables per group

\begin{tabular}{|l|l|l|l|l|l|}
\hline $\begin{array}{l}\text { Brief and stimuli } \\
\text { received }\end{array}$ & $\begin{array}{l}\text { Variable } \\
\text { name }\end{array}$ & $\begin{array}{l}\text { Novice } \\
\text { students (N) }\end{array}$ & $\begin{array}{l}\text { Novice } \\
\text { sketches (N) }\end{array}$ & $\begin{array}{l}\text { Advanced } \\
\text { students (N) }\end{array}$ & $\begin{array}{l}\text { Advanced } \\
\text { sketches (N) }\end{array}$ \\
\hline Fishbone & FB & 18 & 50 & 18 & 44 \\
\hline Abstract & AB & 20 & 56 & 19 & 53 \\
\hline Abstract \& Fishbone & AF & 15 & 42 & 19 & 46 \\
\hline
\end{tabular}

The FB group received a succinct problem description and was given additional time using a diagram to systematically think about the problem's root cause and guide their thought processes. Student designers were first instructed to write observed problems from the initial design brief. After that, they choose from a list of categories to guide the asking of "whys". Students develop their problem frame quite extensively as they engage in problem discovery via a cause-and-effect questioning approach to determine root causes. They were then told to develop How-might-we's (HMW's) from the Fishbone diagram. The $\mathrm{AB}$ group was given a generic brief with abstraction propositions. Hence, groups with abstract representations as stimuli received brief's requirements in a language of simple, generic scientific/physics principles that students can relate to, intending to improve association and transfer (see Table 2). In comparison to the Brief FB, the terms used in Brief AB are hypernyms, meaning they had higher-order words or a semantic relation. The terms in Brief FB are more tangible and relatable, while those in Brief $\mathrm{AB}$ are more conceptual and imaginative. Students in the Brief AF received 
abstract propositions of Brief $\mathrm{AB}$ and next used Fishbone diagrams to identify the underlying/root causes of problems based on observations. As such, this is considered a combined effect brief. Participants were given handouts on the problem framing tool and worked in pairs on the tool before generating one "HMW" opportunity statement each.

\section{Table 2. Design Briefs comparison of design needs/requirements}

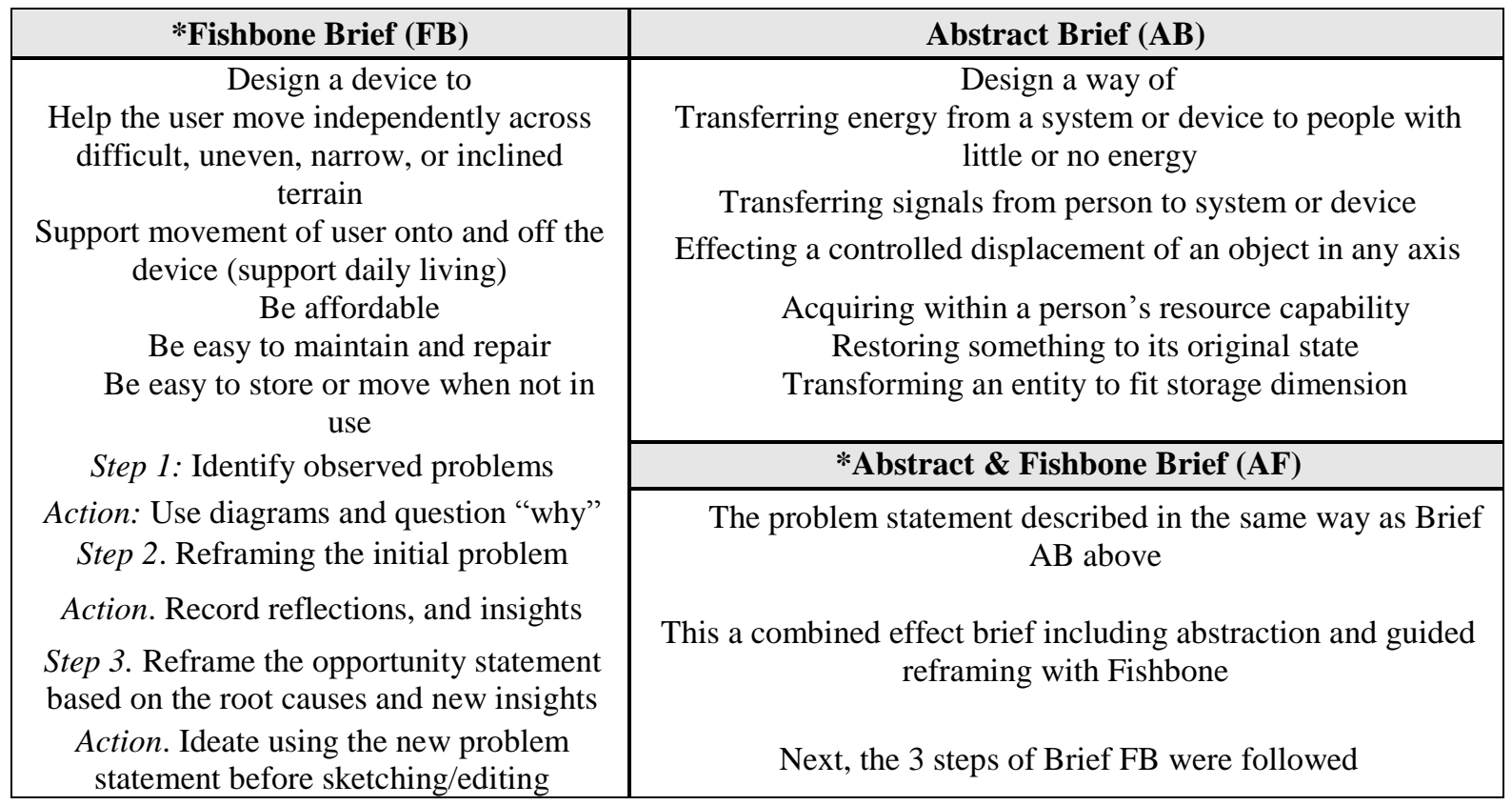

*Students are taught a framework to respond to the brief in addition to the given problem descriptions.

\subsection{Measures of creativity}

To rate the participants' concept drawings' creativity, each drawing was judged for Novelty and Usefulness. The judging was conducted with reference to the consensual technique of creativity assessment (CAT) by Amabile (1996). This technique is based on the ratings of a group of "expert judges", validated as a reliable and consistent evaluation practice among expert judges (Amabile, 1996; Baer, 2008).

Novelty, assesses the originality of the sketches by means of how the idea is different from usual forms of mobility. Novelty was rated using a 1 to 5 Likert type item, with ' 1 ' representing a duplicate idea of an existing product and ' 5 ' representing an extremely novel idea (in Table 3 ).

On the other hand, Usefulness encapsulated multiple facets to include a broader definition by a series of factors of Usefulness (Dean 2006). As such, Usefulness is the mean value of Implementability, and Effectiveness based on equal weighting. An effective design is a solution that improves user's mobility and allows for independent movement across difficult terrains. An implementable design is a solution that can be industrialized with today's technology.

In our study, the student's creative outcomes were assessed by professional and academic expert judges. Three independent judges evaluated concept drawings produced by the students, using a rubric-based system. The total score for each outcome was obtained by the average of the three scores transformed into mean scores representing each metric. The judges used their domain-based expertise to judge the Novelty and Usefulness of the concept drawings without consulting each other during the judging process, in line with existing practices (Baer, 2008). All judges, who were blind to the hypotheses and experimental conditions of the study, had at least ten years of experience in their respective fields. They all went through a training set of numerous drawings for familiarization with the evaluation rubric and process before evaluating the concept sketches. We assumed that after this process, judges shared similar understandings of all creativity metrics to a reasonable degree. The use of the CAT was helpful to provide a framework for expert judges to assess the sketches while maintaining a rigorous definition of creativity scores, namely Novelty and Usefulness. 
Table 3. Assessment rubric

\begin{tabular}{lll} 
Novelty & Level /Example (1) & Level /Example (5) \\
\hline & It is entirely similar & It is completely different \\
Usefulness & Level /Example (1) & i.e., idea is a real surprise \\
\hline Effectiveness & Ineffective & Level /Example (5) \\
& i.e., there was no improvement in mobility & Effective \\
Implementabi & Nonimplementable & i.e., mobility is greatly improved \\
& i.e., industrializing this product is impossiblel & Practically implementable \\
& & i.e., it can be industrialized with existing \\
& knowledge \\
\hline
\end{tabular}

\subsection{Procedure}

We collected data from novice students ( $\mathrm{n}=148$ sketches) and advanced students ( $\mathrm{n}=143$ sketches) in the same academic year who received identical design tasks and were provided with consistent documentation. Each class consisted of around 20 students that contributed up to three sketch ideas. Students dealt with a sketching activity and a short-form survey that sought demographic particulars and allocation for the study. Data were collected across six classrooms, where the experimental procedures were replicated (i.e., time allocated, instructions, number of people per class, and materials provided). The sketch exercise lasted for 15 mins whilst selected classes followed a 40-mins reframing exercise (fishbone conditions) before the sketching exercise proper.

The design brief requested students to design "A device to improve mobility for low-income persons with physical disabilities". Students started by sketching (and annotating) three different concept drawings that offered a solution to the design brief and with guidance from their respective representations to complete the exercise. They were instructed to be as creative as possible with the connotation that in our experiment, 2 metrics create scores for creativity (Novelty \&Usefulness). Participants were informed that the completed sketches would bear no influence on their academic standing or performance.

Normality assumptions were tested on the sample of 291 drawings evaluations via The Shapiro-Wilk. The normality hypotheses failed for both outcome variables $(\mathrm{p}=0.00031)$, while homogeneity of variance was deemed not to be normally distributed $(\mathrm{p}=0.004)$. Given these violations, one-way ANOVA was not appropriate, and thus the non-parametric equivalent to a one-way between-groups analysis of variance (ANOVA), Kruskal-Wallis was used instead as the outcome variables were continuous and interval.

\section{RESULTS}

To address RQ1, we employed pairwise comparisons between the different conditions per expertise level to determine which group is more effective in generating novel and useful solutions. It is shown that novelty illustrates significant differences in-between novice $H(2, \mathrm{n}=148)=6.94, p=.031$ and advanced students $H(2, \mathrm{n}=143)=11.2, p=.004$ mean ranks across different briefs (descriptive data in Appendix: Table 4). Brief AF improved novelty scores for novices; however, Briefs AB were the ones with the highest means in this metric (Figure 1).

The pairwise comparisons indicated strong evidence of a difference between Brief AF and Brief FB $(p=.039)$. No differences were found between the other pairs. Advanced students' novelty scores were also affected by the provision of different briefs. The pairwise comparisons revealed that there were no differences between students' scores in Briefs AF and AB. However, both scored significantly higher than Brief FB (AF-FB, $p=.042$; FB-AB, $p=.004$ ). In Usefulness metric, statistical differences occurred only in the novices' group where although Brief FB ranked higher $\mathrm{H}(2, \mathrm{n}=148)=12.42, p$ $=.002$, it had no statistical difference over the second performing brief in rank (Brief $\mathrm{AB}$ ) in the pairwise comparisons $(p=.289)$. The Usefulness of the outcomes produced by the advanced students showed no statistical significance across the different briefs.

In response to RQ2, we explored whether differences in the creative outcome can be found between students' scores of the two different experience levels per condition. The boxplots in Figure 2 show that advanced students scored higher in each of the different briefs. The novice student bars, however, are the ones with the narrowest range of scores. All differences in the Novelty scores across the levels 
of expertise were statistically significant $H(1, \mathrm{n}=291)=6.94, p=.0001$ (For the pairwise comparisons output see Table 5).
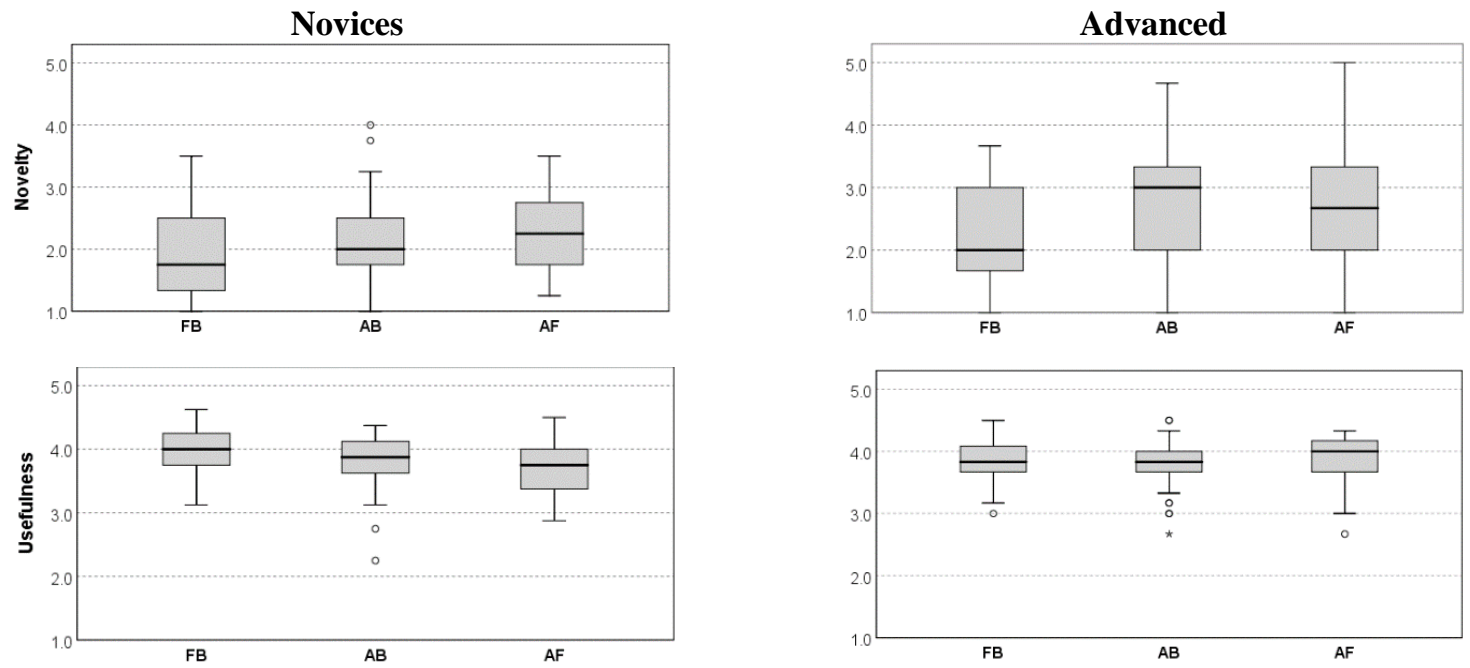

Figure 1. Kruskal-Wallis Test mean ranks per condition (RQ1)

The magnitude of statistical significance in Usefulness mean scores among the three experimental conditions indicates differences only for Brief AF. In this brief, advanced students performed significantly better than the novices $H(1, \mathrm{n}=88)=6.01, p=.0014$. On the other hand, although novice students performed better than advanced students in Briefs $\mathrm{FB}$ and $\mathrm{AB}$, this difference was not statistically significant, as indicated by the pairwise tests (in Table 5).
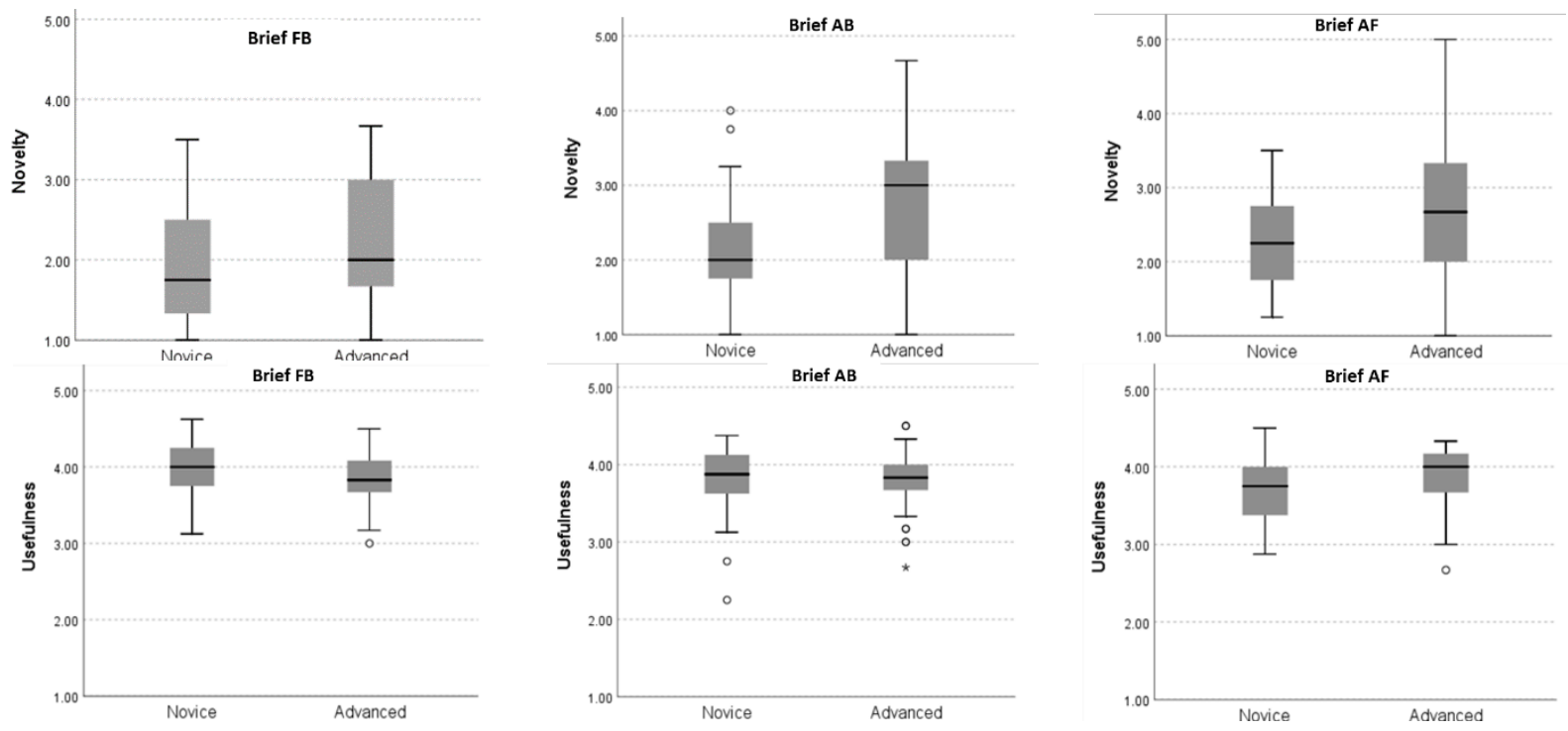

Figure 2. Kruskal-Wallis Test mean ranks across conditions for Novelty and Usefulness

(RQ2)

With respect to RQ3, findings suggest that differences occurred only for the Novelty of the creative outcomes $H(2, \mathrm{n}=291)=16.80, p=.000$. Regarding this metric, solutions of students with Brief AF ranked higher with no significant difference over Brief $A B$ (boxplots in Figure 3), although pairwise results show a statistically significant difference in mean ranks to the Brief $\mathrm{FB}$ (AB-FB, $p=.001$; AF-FB, $p=.001)$. Regarding Usefulness, pairwise comparisons among the three conditions did not show significant differences. This indicates that students' overall scores are not affected by the provision of various stimuli. 

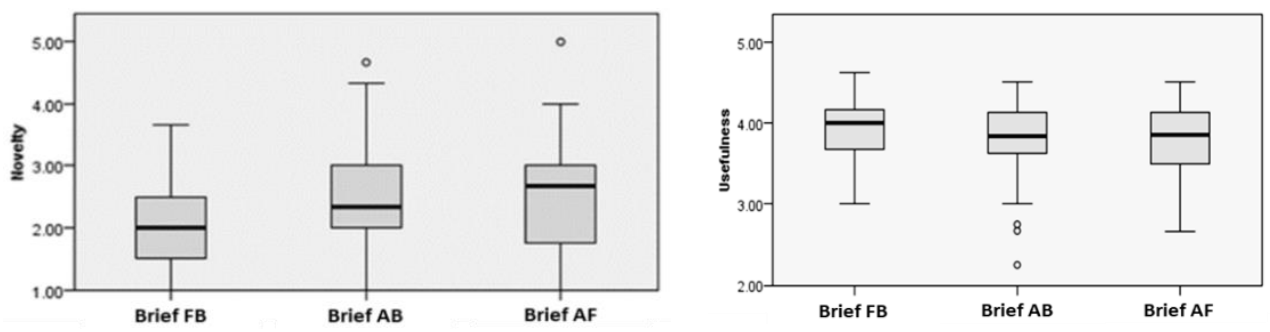

Figure 3. Kruskal-Wallis Test mean ranks across briefs irrespective of expertise (RQ3)

\section{DISCUSSION}

Our first research question RQ1 aimed to explore differences in students' creative outcomes, based on the design briefs they were exposed to and their expertise level. In the case of advanced students, Briefs $\mathrm{AB}$ contributed to producing more novel outcomes compared to the other briefs, while a combination of Briefs $\mathrm{FB}$ and $\mathrm{AF}$ was more helpful for the novices than for the advanced students. Novices who have lesser experience and knowledge benefited from instructions on how to restructure the design problem via the fishbone brief. This probably allowed them to make successful structural mappings and associations to abstract stimuli and the design problem before producing novel solutions. In contrast, the more experienced students did not need further assistance to employ an abstraction strategy to support novel idea solutions.

In RQ2, we found statistically significant differences in the way conditions improve creative outcomes at different levels of expertise. We were anticipating novices to rank higher in Novelty as an earlier multisite analysis among undergraduate and postgraduates concluded (Koronis et al., 2019b). Also, novices have fewer constraints and practical considerations imposed on themselves for contributing to novel solutions (James et al., 2014). However, this aspect was not reflected in their scores, and thus advanced students scored higher in all three briefs for Novelty. Possibly, a considerable amount of experience in design projects and assignments would help novice designers contribute more original and novel ideas and solutions. This result appears to reflect the fact that creativity has been valued and promoted across our design-centric university, leading students to develop novel approaches to design problems throughout their coursework. Novice students took the lead on Usefulness only in Brief FB; however, their outcomes were not significantly better than their advanced counterparts. Thus, novice students' best approach to attaining or overcoming advanced students' performance would be adhering to a guided reframing approach where their experience in producing useful solutions will likely outbalance their limitations in developing novel outcomes.

In response to RQ3, we investigated differences among the design conditions regarding participants' designs creativity, disregarding their expertise level. It was observed that the combined effect of abstraction and guided reframing condition (in Brief AF) improves overall Novelty while the single effect Brief FB improves Usefulness. One reason could be that producing novel designs is a more demanding task than generating useful ones, and therefore exposing teams of novice and advanced students to both types of stimuli, either simultaneously or in sequential rounds, can be of great assistance. On the other hand, the guided reframing technique may enable students to better understand the problem and the initial design requirements, which contribute to improving Usefulness. However, while exposing students to reframing alone produce fewer novel results compared to other conditions. Using a combination of both stimuli may result in the best intermediate option to produce highly novel design solutions with moderate Usefulness.

\section{CONCLUSIONS AND FUTURE WORK}

This study investigated the aid provided by the information contained in three types of briefs aimed to enhance design creativity and explored how students with different levels of expertise can benefit from these. Advanced students performed better on Novelty, scoring higher in all three conditions, while in the Fishbone condition novice students performed slightly better in Usefulness. We are not aware if this effect occurred due to the brief information alone or if it occurred when additional tools such as "HMW's" and problem restructuring were included in Briefs FB and AF. Another limitation is the different processing times set by each of the briefs, which could have affected the observed statistical differences. Future studies should consider designing separate briefs for each of the tools above to 
identify their possible independent effects on the design outcomes. A further possible cause for the difference in the advanced students' performance is that they have been exposed to the university curriculum for a longer period of time. Given that the obtained results suggest that creativity is valued and promoted across the curriculum, that could give the advanced students an advantage as they have had more time to evolve their capacity for deriving novel outcomes throughout their coursework. Implications for design education can be drawn from our findings regarding the studied groups' level of expertise.

Independently of the influence of the design brief conditions investigated, the creativity of the design outcomes might also depend on other variables besides our control. These include, but might not be limited to, individual skills, cognitive styles, motivation, and task dedication. Developing concepts in a limited timeframe may also cause stress for the participants, thereby reducing the creativity of their outcomes. Moreover, as students in the senior year are split further into four major disciplines/pillars, we could further investigate how student designers perform in each of these disciplines to understand the effect of studying in a certain discipline and its effect on creativity. Whether using restructuring or abstraction briefs as pedagogical tools to enhance design creativity or even a combination of both, showed to be dependent on the kind of creativity intended to be promoted.

\section{ACKNOWLEDGEMENTS}

This work is supported by the Singapore University of Technology and Design (SUTD) and the SUTD-MIT International Design Centre (IDC, idc.sutd.edu.sg), project IDG 11600102.

\section{APPENDIX}

Table 1. Descriptive mean ranks scores per brief

\begin{tabular}{|c|c|c|c|}
\hline \multirow{2}{*}{$\begin{array}{l}\text { Briefs } \\
\text { Description }\end{array}$} & \multirow{2}{*}{ Label } & \multicolumn{2}{|c|}{ Dependent Variables } \\
\hline & & Novelty & Usefulness \\
\hline \multirow{2}{*}{ FB } & Novice & 61.99 & 89.75 \\
\hline & Advanced & 55.10 & 70.07 \\
\hline \multirow{2}{*}{$\mathrm{AB}$} & Novice & 78.45 & 72.93 \\
\hline & Advanced & 82.22 & 69.40 \\
\hline \multirow{2}{*}{$\mathrm{AF}$} & Novice & 84.13 & 58.44 \\
\hline & Advanced & 76.39 & 76.85 \\
\hline
\end{tabular}

\section{REFERENCES}

Amabile, T.M. (1982), “The Social-Psychology of Creativity: A Consensual Assessment Technique”, Journal of Personality and Social Psychology, Vol. 43 No. 5, pp. 997-1013

Amabile, T.M. (1996), Creativity in Context, 1st ed., Westview Press, Boulder, CO

Boucharenc, C. G. (2006). Research on basic design education: An international survey. International Journal of Technology and Design Education, 16, 1-30.

Budge, K., Beale, C., and Lynas, E. (2013). A chaotic intervention: Creativity and peer learning in design education. iJADE, Vol. 32, pp. 146-156.

Camburn, B.A., Auernhammer, J.M., Sng, K.H.E., Mignone, P.J., Arlitt, R.M., Perez, K.B., Huang, Z., Basnet, S., Blessing, L.T. and Wood, K.L. (2017), Design Innovation: A Study of Integrated Practice. No. 58219, p. V007T006A031.

Carlgren, L., Rauth, I. and Elmquist, M. (2016), "Framing Design Thinking: The Concept in Idea and Enactment", Creativity and Innovation Management, Vol. 25 No. 1, pp. 38-57.

Casakin, H., and Kreitler, S. (2008) Correspondences and divergences in creativity evaluations between architects and students. Environment and Planning B: Planning and Design, Vol. 35, pp. 666-678.

Casakin (2010). Visual analogy, visual displays, and the nature of design problems: the effect of expertise. Environment and Planning B: Planning and Design, Vol. 37, pp. 170-188.

Casakin, H. \& Kreitler, S. (2010) Motivation for Creativity in Architectural Design and Engineering Design Students: Implications for Design Education. International Journal of Technology and Design Education, Vol. 20, No. 4, 477 493.

Chen, W. (2016). Exploring the Learning Problems and Resource Usage of Undergraduate Industrial Design Students in Design Studio Courses. International Journal of Technology and Design Education, Vol 26, pp. 461-87

Christiaans, H., \& Dorst, K. H. (1992). Cognitive models in industrial design engineering: a protocol study. Design theory and methodology, Vol. 42 No. 1, 131-140. 
Christiaans, H., \& Venselaar, K. (2005). Creativity in Design Engineering and the Role of Knowledge: Modelling the Expert. International Journal of Technology and Design Education, Vol. 15 No. 3, pp. 217-236.

https://dx.doi.org/10.1007/s10798-004-1904-4

Coyne, R. (1997). Creativity as commonplace. Design Studies, Vol. 18, pp. 135-141.

Craft, A. (2006). Fostering Creativity with Wisdom, Cambridge Journal of Education, Vol. 36 No. 3, pp. 351-62.

Dean, D., M. Hender, J., Lee Rodgers, T., \& Santanen, E. (2006). Identifying Quality, Novel, and Creative Ideas: Constructs and Scales for Idea Evaluation. Journal of the Association for Information Systems, Vol. 7 No. 10, pp. 646-699. http://dx.doi.org/10.17705/1jais.00106

Derbaix, C., \& Vanhamme, J. (2003). Inducing word-of-mouth by eliciting surprise? A pilot investigation. Journal of Economic Psychology, 24, 99-116.

Dominowski, R L. (1995). Productive problem solving. In: The Creative Cognition Approach, Cambridge, MA, pp. 73-95.

Dorst, K. (2015). Frame innovation: Create new thinking by design. MIT Press, Cambridge, MA,

Goldstone R, Sakamoto Y (2003) The transfer of abstract principles governing complex adaptive systems. Vol. 46. http://dx.doi.org/10.1016/S0010-0285(02)00519-4.

Goncalves, M.; Cardoso, C.; Badke-Schaub, P. 2014, What inspires designers? Preferences on inspirational approaches during idea generation. Design Studies, Vol. 35 No. 1, pp. 29-53. https://doi.org/10.1016/j.destud.2013.09.001

Hong, E., \& Milgram, R. M. (2008). Preventing Talent Loss. New York: Routledge.

Ishikawa, K., (1982), What is Quality Control? Prentice Hall, Englewood Cliff, New York, NY.

James, T.J.Y., Kuan, Y.K., Parveen, H., Huang, Z.X., Ganeshkumar, R., Behera, J., Sanaei, R., Otto, K. and Hölttä-Otto, K. (2014), “An Overview of Design Cognition between Experts and Novices”, In: International Conference on Advanced Design Research and Education 2014, Singapore, pp. 156-160. http://dx.doi.org/10.3850/978-981-091348-9_041

Koronis, G., Silva, A., Kang, J., \& Yogiaman, C. (2020). How to Best Frame A Design Brief to Maximize Novelty and Usefulness in Idea Generation. Proceedings of the Design Society: DESIGN Conference, Vol 1, pp. 1745-1754. https://doi.org/10.1017/dsd.2020.77.

Koronis, G., Chia, P.Z., Kang, J., Siang, K., Silva, A., Yogiaman, C. and Raghunath, N. (2019), “An Empirical Study on the Impact of Design Brief Information on the Creativity of Design Outcomes with Consideration of Gender, and Gender Diversity", Journal of Mechanical Design. Vol. 141 No. 7 pp. 071102. http://dx.doi.org/10.1115/1.4043207.

Koronis, G., Meurzec, R. W., Silva, A., Leite, M., Henriques, E., \& Yogiaman, C. (2019b). Cross-Cultural Differences in Creative Ideation: A Comparison between Singaporean and Portuguese Students. Proceedings of the Design Society: International Conference on Engineering Design, Vol. 1 No. 1, pp. 89-98. http://dx.doi.org/10.1017/dsi.2019.12

Linsey, J. S., Markman, A. B., \& Wood, K. L. (2012). Design by Analogy: A Study of the WordTree Method for Problem Re-Representation. Journal of Mechanical Design, Vol. 134 No. 4, pp. 041009. https://doi.org/10.1115/1.4006145.

Linsey, J.S., Tseng, I., Fu, K., Cagan, J., Wood, K.L. and Schunn, C. (2010), “A Study of Design Fixation, Its Mitigation and Perception in Engineering Design Faculty”, Journal of Mechanical Design, Vol. 132 No. 4, pp. 041009.

Linsey, J. S., K. L. Wood, and A. B. Markman. 2008. "Modality and representation in analogy.” Artificial Intelligence for Engineering Design, Analysis and Manufacturing. Vol. 22 No. 2, pp. 85-100. http://dx.doi.org/10.1017/S0890060408000061.

Madni, A. (2012). Elegant Systems Design: Creative Fusion of Simplicity and Power. Vol. 15 No.3, pp. 347-354. https://doi.org/10.1002/sys.21209.

Meurzec, R.W., Koh, B., Koronis, G., Kang, J., Yogiaman, C., Silva, A. (2019). Assessing Regulatory Focus Differences in Creative Ideation: An Examination of Prevention and Promotion Mindsets on Novelty and Usefulness, Proceedings of the Design Society: International Conference on Engineering Design, Vol. 8 No. 1 , pp. 49-45. http://dx.doi.org/10.1017/dsi.2019.8.

Moreno, D.P., Blessing, L.T., Yang, M.C., Hernández, A.A. and Wood, K.L. (2016), "Overcoming design fixation: Design by analogy studies and nonintuitive findings", Artificial Intelligence for Engineering Design, Analysis and Manufacturing, Vol. 30 No. 2, pp. 185-199. https://doi.org/10.1017/S0890060416000068

Parnes, S.J. (1967) Creative Behavior Guidebook. Scribners, New York.

Rittel, H., and Melving, W. (1984). Planning problems are wicked problems. In N. Cross (Ed.). Developments in design methodology. New York: John Wiley \& Sons, pp. 123-143.

Ree, M. J., Carretta, T. R., \& Teachout, M. S. (1995). Role of ability and prior knowledge in complex training performance. Journal of Applied Psychology, 80(6), pp. 721-730. https://dx.doi.org/10.1037/0021-9010.80.6.721

Sarkar, P., \& Chakrabarti, A. (2011). Assessing design creativity. Design Studies, Vol. 32 No. 4, pp. 348-383. https://dx.doi.org/10.1016/j.destud.2011.01.002.

Seelig, T. L., 2015, InGenius: A Crash Course on Creativity, HarperOne, New York.

Schön, Donald A. (1983). The reflective practitioner: How professionals think in action. New York: Basic Books.

Valkenburg, A. C. (2000). The reflective practice in product design teams. Technische Universiteit Delft. http://resolver.tudelft.nl/uuid:8bbe62ab-e761-46f7-b386-3ead14a9d56d

Zahner, D., Nickerson, J. V., Tversky, B., Corter, J. E., \& Ma, J. (2010). A fix for fixation? Rerepresenting and abstracting as creative processes in the design of information systems. Artificial Intelligence for Engineering Design, Analysis and Manufacturing, Vol. 24 No .2, pp 231-244. http://dx.doi.org/10.1017/S0890060410000077. 